\title{
Using Combined Close-Range Active and Passive- Remote Sensing Methods to Detect Sinkholes
}

\author{
Naftly Goldshleger ${ }^{1^{*}}$, Uri Basson ${ }^{2}$, Shlomo Fastig $^{3}$ and Ilan Azaria ${ }^{4}$ \\ ${ }^{1}$ Department of Civil Engeneering, Ariel University, Ariel, Israel \\ ${ }^{2}$ GeoSence Ltd., Even-Yehuda, Israel \\ ${ }^{3}$ Sensing Div., Soreq NRC, Yavne, Israel \\ ${ }^{4}$ SensingGis Ltd., Tyokin, Tel Aviv, Israel
}

*Corresponding author: Naftly Goldshleger, Department of Civil Engeneering, Ariel University, Ariel, Israel, Tel: 972-506241802; E-mail: Goldshleger1@gmail.com

Rec date: December 27, 2017; Acc date: January 03, 2018; Pub date: January 05, 2018

Copyright: (c) 2018 Goldshleger N, et al. This is an open-access article distributed under the terms of the Creative Commons Attribution License, which permits unrestricted use, distribution, and reproduction in any medium, provided the original author and source are credited.

\begin{abstract}
In the Dead Sea region of Israel, sinkholes collapse can be observed easily due to the large number of sites. The continuous decrease in Dead Sea level over the last 30 years, caused a substantial increases the sinkhole activity (more than 5,500 sinkholes upper layer collapse). Sinkholes of up to $50 \mathrm{~m}$ diameter are found to be clustered in sites with variable characteristics. In this research, we have developed methods for prediction of sinkholes appearance by using mapping and monitoring methods based on active and passive remote-sensing means. These methods are based on measurements from several instruments including field spectrometry, geophysical ground-penetration radar (GPR) and a frequency domain electromagnetic (FDEM) instrument. Field spectrometry was used to compare the spectral signatures of soil samples collected near progressing sinkholes and those taken in regions with no visible occurrence of sinkholes. Active remote sensing showed higher electrical conductivity and soil moisture in the former regions. Measurements were taken at different time points to monitor the progress of an "embryonic" sinkhole. The research steps included (i) review of previous published literature, (ii) mapping of regions with an abundance of sinkholes in various stages, and areas that are vulnerable to them, (iii) data analysis and development of warning indicators, accessible information to the scientific community.
\end{abstract}

The result derived from this research indicates the possibility to build a pre-warning tool to detect the formation of sinkholes.

Keywords: Sinkhole; Passive remote sensing; Active remote sensing; Spectroscopy; Frequency domain electromagnetic; Groundpenetration radar

\section{Introduction}

The Dead Sea basin located in the Dead Sea Transform, is exposed to the destructive process of sinkhole collapse. A substantial increase in sinkhole activity in the last two decades has resulted from the continuous decrease in the Dead Sea's level. The near-surface layers of the Dead Sea basin consist of massive sedimentary rocks-dolomite, limestone and others [1] at the margins, and alluvial and evaporate materials in the basin. A sinkhole is a topographic depression caused by the sudden or gradual collapse of underground rock layers. Sinkhole formation occurs in many parts of the world (e.g., Spain, United States, Italy, and Thailand) [2]. The mechanism responsible for the appearance of sinkholes is dissolution of soluble rocks and creation of subsurface cavities [3,4] and these mechanical processes are influenced by erosion processes [5]. The dissolved rock is usually a carbonate [6] with a rather slow dissolution rate, or salt, with a much higher dissolution rate [7-9]. Salt outcrops are rare and produce landscapes that are typically associated with karst formations, characterized by local sinkholes, valleys and underground streams $[10,11]$. Evaporates vary largely in their solubility and dissolution rates. Salt (halite, $\mathrm{NaCl}$ ), a common mineral and rock at the subsurface, is $>100$ times more soluble than gypsum. Salt is soluble in most aquatic environments. Therefore, the subsurface dissolution of salt and collapse of the overlying material in sinkholes may be extremely large in salty rocks. Remote-sensing approaches have been presented to monitor the processes of subsurface salt dissolution and associated sinkhole hazards along the Dead Sea coast [1]. These methods have allowed delineating salt-layer boundaries, estimating the layer's porosity distribution, finding cavities within the layer, identifying deformations in the overlying sediments and detecting caves using multiple geophysical methods [12]. Collapsed sinkholes started to appear along the Dead Sea coast in Israel and Jordan in the early 1980's. Sinkhole development has significantly accelerated since 2000, with the abrupt occurrence of over 5,500 of them [13]. This regionalscale collapse is attributed to the rapid decline of the Dead Sea level (1 $\mathrm{m} / \mathrm{yr})[1,14,15]$. This decline, which has exceeded $40 \mathrm{~m}$ since the early 1930 's, reflects human activities, such as interception of the freshwater supply from the Jordan River and maintenance of large evaporation ponds by Dead Sea mineral industries in Jordan and Israel.

Based on geological and hydrological evidence [14,16], sinkholes in the Dead Sea are formed by salt-layer dissolution [14,17]. Sinkhole formation is also sometimes associated with the fault structure of the Dead Sea basin, as well as land subsidence caused by compaction of fine-grained sediments (clay and silt) in the upper part of the sedimentary fill. Some authors have associated the development of subsurface cavities to the variations in Dead Sea level over the past four decades $[5,14,16]$. Recent studies have related the formation of subsurface cavities to underground water flow. The cavity develops 
upward due to underground flow, forming a sinkhole when the collapsed level reaches the surface [18]. The development of subsurface cavities is sometimes correlated with the presence of geotectonic faults $[19,20]$. To assess the presence of faults or sinkholes, a high-resolution three-dimensional (3D) seismic reflection survey was carried out between the Dead Sea shoreline and Route 90 (which runs parallel to the western shore of the Dead Sea), where sinkholes develop in the alluvial fan and lacustrine deposits. Processing of the 3D time-volume data showed sub-horizontal coherent reflectors at approximately 35-70 $\mathrm{m}$ depth [17]. The authors suggested a possible link between the revealed fault and some sinkholes. Large sinkholes that are visible on the surface can reach diameters of $25 \mathrm{~m} \mathrm{[13],} \mathrm{and} \mathrm{several} \mathrm{of} \mathrm{them}$ together can form mega-sinkholes which are hundreds of meters in length. More than 5,500 sinkholes [13] have already developed in the Dead Sea basin that are likely related to the existence of underground cavities created by salt dissolution [21].

Electromagnetic (EM) methods were used by Ezersky et al. [22] to monitor sinkholes and subsoil information. That author used a transient EM method to map the electrical resistivity of the subsurface through the Nahal Hever South area, which is characteristic of the Dead Sea coast. Those measurements allowed detailed differentiation of layers (clay, salt, etc.) in the subsurface based on their bulk resistivity. Ezersky et al. $[19,20]$ found that sinkhole development is linked to the salt edge in the Dead Sea area.

\begin{tabular}{|l|l|l|}
\hline Method & Task for which used & Frequencies/EM spectral region \\
\hline $\begin{array}{l}\text { Frequency domain Electromagnetic } \\
\text { (FDEM) }\end{array}$ & $\begin{array}{l}\text { Measuring subsurface electrical conductivity and magnetic } \\
\text { susceptibility }\end{array}$ & $625 \mathrm{~Hz} ; 1,975 \mathrm{~Hz} ; 6,125 \mathrm{~Hz} ; 19,175 \mathrm{~Hz} ; 60,025 \mathrm{~Hz}$ \\
\hline Ground-penetration radar (GPR) & Imaging the subsurface for sinkhole identification & $100 \mathrm{MHz}$ \\
\hline Analytical Spectral Device (ASD) & Soil mineralogy, soil moisture of near- surface soil layers & $350-2500 \mathrm{~nm}$ \\
\hline
\end{tabular}

Table 1: Characteristics of the close-range remote-sensing instruments used in this study.

Forward modeling results indicated that both high resistivity and residual gravity anomalies are associated with subsurface de compaction of the soil mass and deep cavities at the sinkhole site. The sinkhole was slowly moving toward the Dead Sea Ezerzky et al., $[19,20]$. Similar studies carried out in the Ghor Al-Haditha area (Jordan) showed that the sinkholes there are also arranged along the winding line conforming to the salt edge $[19,20]$. Geomorphic changes, including sinkhole development, can be extremely rapid, particularly in areas where human activity alters groundwater circulation [1]. The sinkholes in the Dead Sea area form relatively quickly; they influence the shape of the sea coast, cause changes in the soil and water, and affect crop and vegetation status, along with damage to the infrastructure. In this study, we used active and passive remote-sensing methods (Table 1) to monitor sinkhole formation before it is complete and exposed to the surface. We further localized the forming sinkholes both temporally and spatially.

\section{Materials and Methods}

\section{Study area and sampling methods}

In the first stage of the primary survey, four regions along the west coast of the Dead Sea were tested as potential research sites, based on the presence of surface subsidence, and the structural and mechanical properties of the soil and underground rock (Figure 1). Soil samples were collected from all of the plots (study areas) for laboratory analysis and spectral measurements. In the second stage, we chose the area near Ein Gedi Hot Springs for our research. Subsamples were collected at two different times. Figure 2A describes the Ein Gedi locations: "Ein Gedi South" was located about 400 m south of Ein Gedi Hot Springs, where meaningful sinkholes are visible. The plots were divided into a matrix size of $60 \times 70 \mathrm{~m}$, and samples were taken at $10 \mathrm{~m}$ intervals (Figure 2B). Each sampling point was defined using a benchmark.



Figure 1: Research regions of the primary survey.

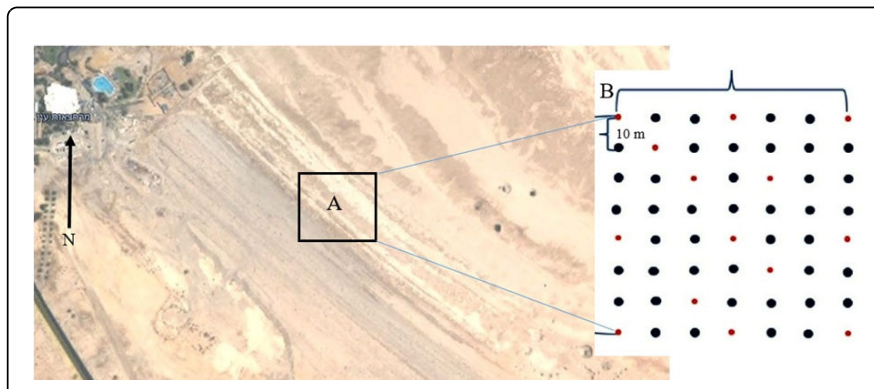

Figure 2: (A) Research plot "Ein Gedi South". (B) Plot matrix of $60 \times$ $70 \mathrm{~m}$; samples were taken at $10 \mathrm{~m}$ intervals. The red points represent soil subsamples of the plot sample; the blue points represent GPR and FDEM measurements. 


\section{Methods}

The analysis involved active and passive remote-sensing methods and chemical analyses of the soil samples. An Analytical Spectral Device (ASD) field spectrometer was used, which covers the EM spectral region $(350-2500 \mathrm{~nm})$ and consists of 2,151 bands. The spectral sampling interval was $1.4 \mathrm{~nm}$ in the $350-1000 \mathrm{~nm}$ range, and 2 $\mathrm{nm}$ in the $1000-2500 \mathrm{~nm}$ range. The channel width (FHMW) was 3 $\mathrm{nm}$ in the $350-1000 \mathrm{~nm}$ range, and $10 \mathrm{~nm}$ in the $1000-2500 \mathrm{~nm}$ range. There were three sensors for three sensitive areas along the visible (VIS)-near infrared (NIR)-shortwave infrared (SWIR) spectral regions, with an optical fiber length of $1.4 \mathrm{~m}$, and a field of view (FOV) of $25^{\circ}$ without lenses. The instrument scans very rapidly, acquiring single spectra in milliseconds via its fiber-optic input. In recent years, there has been an increase in the use of active remote-sensing tools such as GPR (Figure 3a) and subsurface FDEM (Figure 3b) systems for measuring the subsurface EM velocity and dielectric constant (GPR), and the EC profile and magnetic susceptibility (MS) of the subsurface (FDEM).

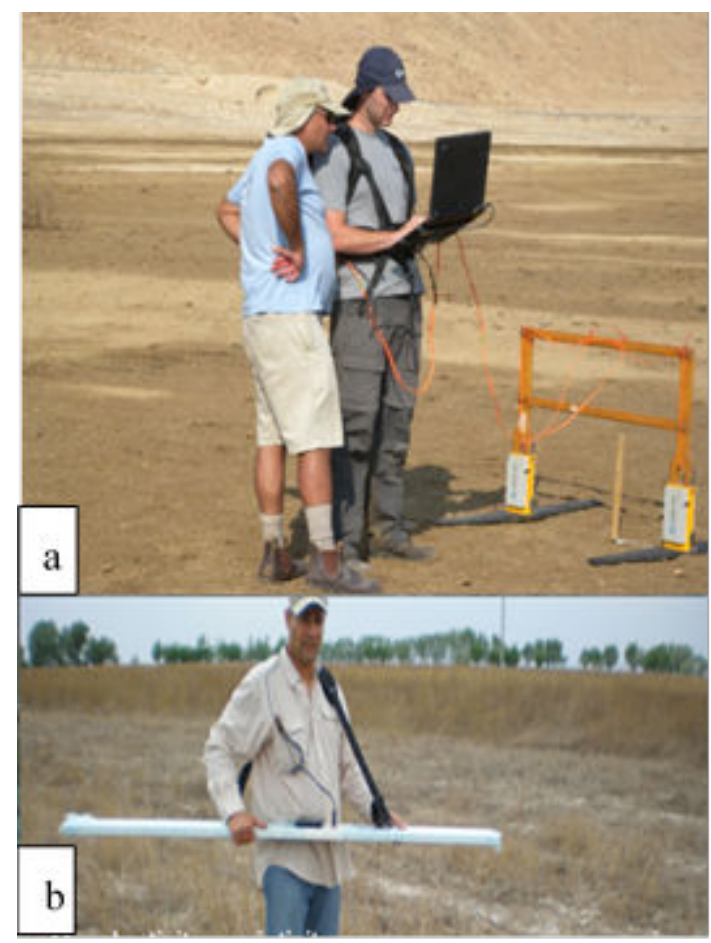

Figure 3: RAMAC GPR (a) and Gem-2 FDEM (b) measurements in the study area.

The FDEM method provides a geophysical tool for measuring EC and MS (apparent values) of subsurface rocks, soils and minerals. The FDEM method involves generating EM fields that induce alternating subsurface eddy currents, which in turn cause the subsurface materials to form relative magnetic fields. By measuring these magnetic fields, apparent subsurface properties such as EC and MS can be deduced. EC depends on the soil and rock matrix, percent saturation, and conductivity of pore fluids. The FDEM instrument provides two measurement values simultaneously-the quadrature component which is strongly dependent on the EC, and the in-phase component, which responds strongly to MS. FDEM has distinct advantages over many other techniques [23]. In this study, we used a Gem-2 sensor operated in multi frequency mode with the following five frequencies: $625 \mathrm{~Hz} ; 1,975 \mathrm{~Hz} ; 6,125 \mathrm{~Hz} ; 19,175 \mathrm{~Hz} ; 60,025 \mathrm{~Hz}$. There is a connection between frequency and penetration depth such that the lower the frequency, the deeper the penetration. The maximum penetration depth achieved was $10-15 \mathrm{~m}$ and the minimum was $2-3 \mathrm{~m}$. The size of the spatial resolution changed from a few centimeters up to $10 \mathrm{~cm}$ at $3 \mathrm{~m}$ depth. The first stage of data processing aimed to reduce the spikes (due to metal objects and field obstacles) and smooth the data. The smoothing operation was iterative at different levels to preserve the accuracy of the raw data. In the second stage, in-phase and quadrature values were converted into apparent MS and apparent EC, respectively. Data gridding was performed in the third stage to produce maps.

In GPR methods, EM waves serve to image the subsurface by transmitting radar pulses into the ground and receiving the signal returning from the interfaces below, to map subsurface layers and moisture content [24]. GPR can provide continuous high-resolution profiling of subsurface features such as geological features, recent faults and more [21]. In the last decade, numerous sedimentological studies have used GPR to reconstruct the nature of sedimentary processes $[25,26]$. Here, a RAMAC GPR was operated at a nominal center frequency of $100 \mathrm{MHz}$ to create subsurface-profile images and to detect subsurface sinkholes, soil-rock discontinuities and variations in water content. A series of cross sections were taken at sample intervals of $0.25 \mathrm{~m}$ along the profiles to obtain radar-reflection images, to an average depth of about 7-10 m.

\section{Research hypotheses and flowchart}

Sinkhole formation is a complex process, with certain physical and chemical soil properties as significant components. These features can be monitored by remote sensing (passive/active) and spectroscopy. Combining these methods improves the ability to identify early stages of sinkhole development. The study was performed in three stages (Figure 4).

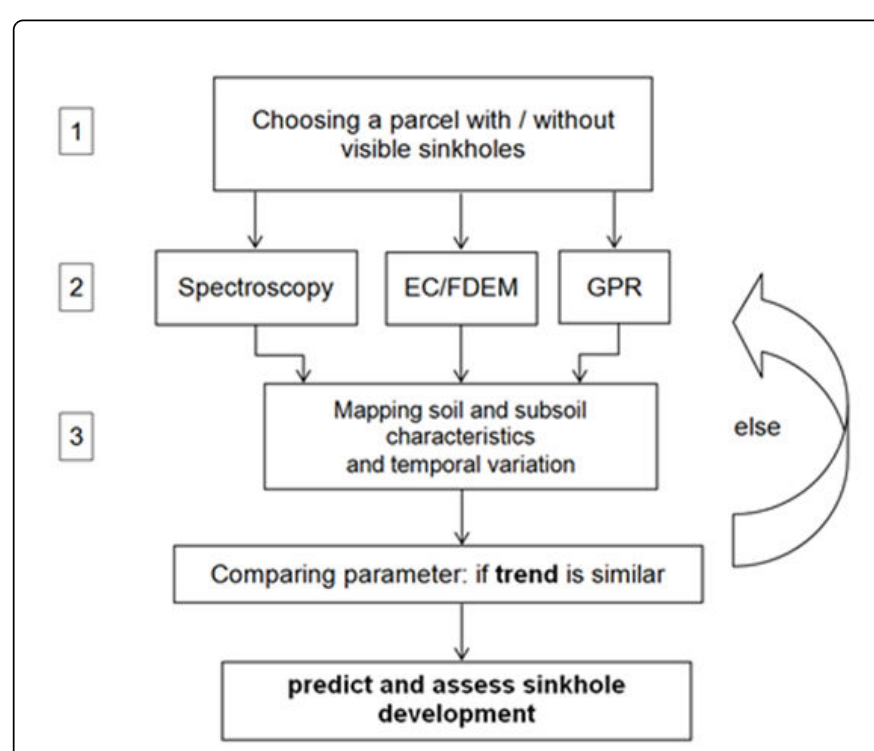

Figure 4: Research flowchart. 
The first consisted of defining the tested areas. The second consisted of integrated information-gathering for simultaneous information acquisition from the different remote-sensing methods, both passive and active. These methods provided an understanding of all of the parameters that favor sinkhole formation and results were compared to references of the processed ground sections to a depth of approximately $15 \mathrm{~m}$. The third stage included the production process and drawing conclusions based on data results.

\section{Spectral soil properties of the study regions}

Figure 5 shows the continuum removal of the average spectral measurements of soils from the study regions in the Dead Sea (see Figure 1 for location of spectral measurements). A comparison between samples allowed classifying the regions into two groups: (i) Mitzpe Shalem (Tmarim field) (Figure 1, group 1, northern region), and (ii) Mineral Beach, Shemurat Kane and Ein Gedi (Figure 1, group 2 , southern region). This classification was based on water absorption in the $1350-1500 \mathrm{~nm}$ and $1750-1900 \mathrm{~nm}$ spectral regions. Note that the Mitzpe Shalem sample also varied at $2350 \mathrm{~nm}$ and $2250 \mathrm{~nm}$. The northern region is characterized by sandy soil (the density and strength of the sand layers is unknown) with high permeability to water. The southern region is characterized by clayey soil with high water-adsorption capacity and low permeability. According to laboratory analyses, $40 \%$ of the soil sample from the southern region was characterized by a grain size smaller than $0.034 \mathrm{~mm}$. In the northern region, only $10 \%$ of the soil sample had a grain size smaller than $0.034 \mathrm{~mm}$. Soil moisture content in the northern region was lower than that in the southern region.

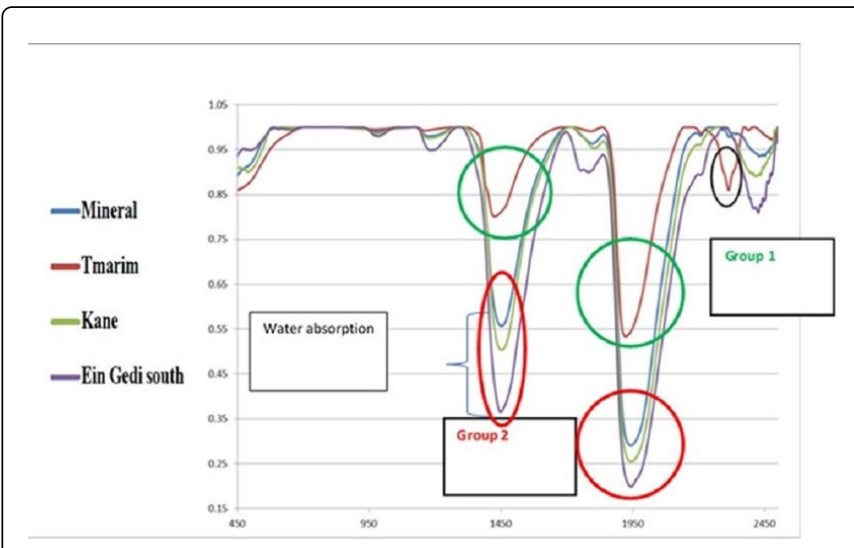

Figure 5: Continuum removal of the average spectral measurements of soils from the study regions along the Dead Sea.

\section{Analysis of EC values as an indicator of ground section sinkholes for micro-zone monitoring}

The "Ein Gedi South" plot was mapped to about $15 \mathrm{~m}$ depth on different dates (Figure 6a and 6b) for $625 \mathrm{~Hz}$ : the red-purple color indicates high EC values of more than $3400 \mathrm{mS} / \mathrm{m}$; the bluegreen color indicates relatively low EC values of less than $2400 \mathrm{mS} / \mathrm{m}$. The northeast purple strip in Figure 6 represents an area close to a sinkhole developing on the surface. This strip is expected to spread to the southwest of the areas shown in purple and red. Figure 7 shows NE-SW EC profiles for the two measurement dates presented in Figure 6.

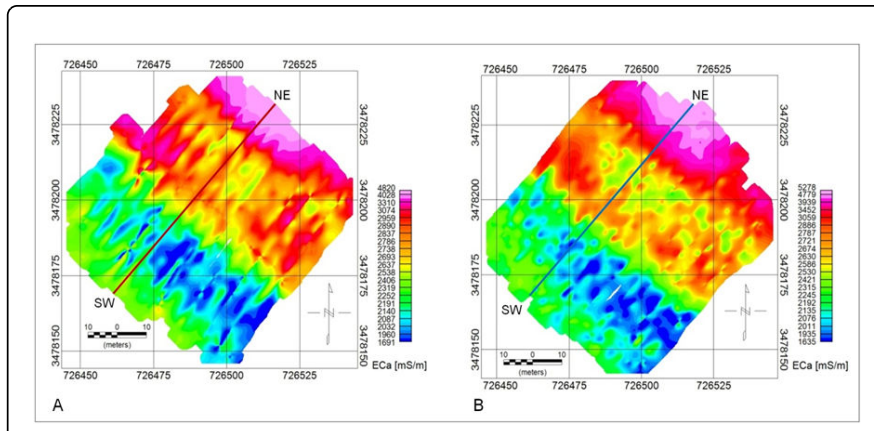

Figure 6: FDEM mapping of the spatial variance of the EC values in the "Ein Gedi South" plot, for two measurement dates: 11 Nov 2011 (A), 12 Apr 2012 (B).

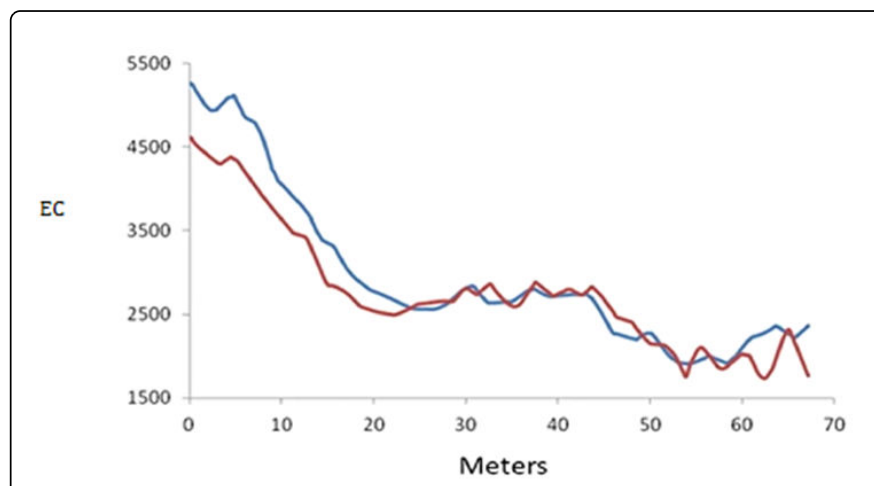

Figure 7: NE-SW EC profiles for the two measurement dates presented in Figure 6.

The "Ein Gedi South" plot was mapped and sampled on two different dates: 11 Nov 2011 and 12 Apr 2012. The mapping was conducted at five different frequencies from 625 to $60,025 \mathrm{~Hz}$, at depths of between 0 and $15 \mathrm{~m}$, to study the sinkhole-formation mechanism on spatial and temporal scales. A comparison of measurements from the two samplings showed expansion of the sinkhole area at the second time point, emphasized by the pink-purple color in the northeastern part of the area (Figure 6). Moreover, higher EC values were observed at the second time point. Analysis of other frequencies gave a similar picture, with the area being divided into three regions.

In the "Ein Gedi South" plot, sinkholes were observed on the surface (final stage of development) and in a highly devolved (intermediate) stage. In "Ein Gedi North", no sinkholes were observed on the surface. A low EC level was observed in the western region and a high EC level in the eastern region of both plots. Unlike the "Ein Gedi North" plot, in "Ein Gedi South", there was continuity of the EC values and the axis of progression was clearer. Moreover, a comparison of the two dates showed that in November, the western region of "Ein Gedi South" was stable, with no significant changes in EC values between the two time points (Figure 6).

\section{GPR analysis}

Cross-sectional reflection imaging was monitored by GPR at a nominal frequency of $100 \mathrm{MHz}$ to achieve good penetration resolution 
to an effective depth of about $10 \mathrm{~m}$ (Figure 8). The profiles were processed in different ways using band pass average=median, and average removal filters with different gains. The raw data (without any filter, aside from the display parameters) were presented for comparison. A vertical cross section was generated at problematic sites and the soil-profile layers were interrelated. Figure 8 presents the GPR cross sections. Two different analyses are presented for each section: the first (Figure 8a) highlights the areas of relatively high moisture near the sinkholes and near the surface. The second highlights the presence of sinkholes in cross section relative to an area without sinkholes (Figure $8 \mathrm{~b}$ ). In Figure $8 \mathrm{a}$ and $8 \mathrm{~b}$, the horizontal scale shows the location of the measurements on the surface and along the cross sections, and the vertical scale shows the different depths of the reflectance measurements. The reflectance strengths are represented by color-plate cuts, with positive amplitudes in black and negative amplitudes in blue tones. A cross section taken in April 2012 at the same location in "Ein Gedi South" (Figure 8c) was compared to the October 2011 analyses, to monitor the development of sinkholes in the area. In the western part, a new sinkhole can be seen right at the beginning of the section, and the development of this existing sinkhole at depth was observed.

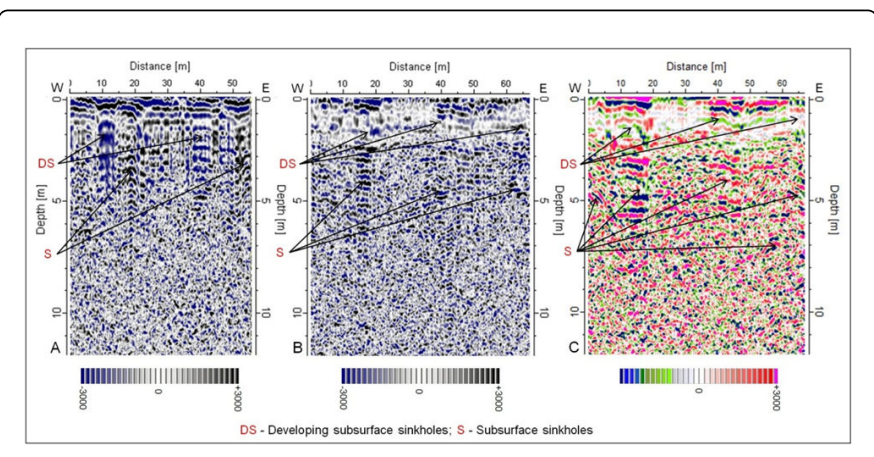

Figure 8: GPR profiles of "Ein Gedi South" plots highlighting areas of high moisture near sinkholes (a) and areas with and without sinkholes (b), both measured in October 2011, and the same area in April 2012 (c).

It should be noted that the temporal changes in moisture content are found in limited locations within the plot. These changes, which are limited in scope rather than covering the complete area, are associated with the development of local subsurface sinkholes (and not to the possibility of reduced evaporation or increased moisture input, such as due to precipitation or groundwater table changes that are expected to occur throughout the area).

\section{Discussion}

\section{Spectral analysis of soil samples as a tool for mapping and detecting sinkhole hazard}

The spectral properties of the soil collected at the research sites enabled their classification into two geographical groups: northern site and southern site. This classification was in agreement with Yechieli et al. (2002), who stated that in the northern part of the Dead Sea, the salt layer is either limited in extent or non-existent, whereas it is abundant in the southern part. Based on our results and earlier studies, it can be assumed at this stage that spectroscopic and hyperspectral aerial surveys will contribute to the finalization of the maps of sinkhole evolution in time and space. Our analysis revealed that spectroscopy can replace laboratory soil and mineralogy analyses for the mapping and classification of soil in the Dead Sea region.

\section{Explanation for changes in EC within plots}

The different measured EC values divided the area into a western region with lower EC values and an eastern region with higher EC values. These differences might be explained by the structural diversity of the soil cross section. The western region is characterized by sandy soil (the density and strength of the sand layers is unknown) with high permeability to water. The eastern region is characterized by clayey soil with high water-adsorption capacity and low permeability. Structural diversity might also exist due to the presence of buried underground soils.

\section{Explanation for the differences in subsurface reflectance values between "Ein Gedi South" and "Ein Gedi North" plots}

Subsurface reflection data results using GPR showed spatial changes resulting from the expansion of a sinkhole, identified by the time interval between the radar measurements. For example, in the eastern part of the "Ein Gedi South" plot, FDEM measurements and radar tools indicated a general expansion of the sinkhole area, with a region of potential sinkhole development to the southwest.

\section{Conclusions}

Combining remote-sensing methods enabled locating existing subsurface sinkholes, mapping them, and identifying areas with potential for new sinkhole development. Combining the various features of the active and passive methods enabled efficient mapping and monitoring of sinkholes at different developmental stages. This is because sinkhole formation is influenced by environmental factors in the subsurface soil, as seen in the layer cross sections.

Soil samples were taken from various sites on the shore of the Dead Sea, mainly the Ein Gedi Hot Springs ("South" and "North"), and their composition and characteristics were determined. Laboratory and remote-sensing analyses carried out on samples taken from the areas in which changes were monitored enabled distinguishing features, especially at sites where the soil might be thin. Initial results showed indicators on the surface of areas in which sinkholes are developing. These indicators were characterized by spectral signatures found at 1450, 1950, 2200 and $2300 \mathrm{~nm}$. These results provide a potential direction for future research. The active and passive remote-sensing methods used in this study enabled monitoring and localizing sinkholes temporally and spatially.

The results indicated periodically detectable changes and, combined with accumulated knowledge of existing sinkhole locations, should enable predicting new sinkhole formation. Designers and engineers might implement the combined passive and active remote-sensing methods used in this study to plan and build better infrastructures on the ground and in the subsurface.

The methods presented in this study should be further developed, in combination with other approaches, such as hyperspectral mapping with modern and advanced sensors, thermal mapping, testing groundwater recharge in sinkholes and its correlation with EC and reflectance values, and combining hydrological and meteorological information with rainfall-runoff relationships. 


\section{References}

1. Frumkin A, Ezersky M, Al-Zoubi A, Akkawi E, Abueladas AR (2011) The Dead Sea sinkhole hazard: Geophysical assessment of salt dissolution and collapse. Geomorphology 134: 102-117.

2. Parise M, De Waele J, Jourde HA (2014) A review on natural and humaninduced geo hazards and impacts in karst. Earth Sci Rev 138: 61-88.

3. Galloway D, Jones DR, Ingberitsen SE (1999) Land subsidence in the United States. US Geological Survey Circular 1182: 177.

4. Gutiérrez F, Cooper AH (2002) Evaporite dissolution subsidence in the historical city of Calatayud, Spain: Damage appraisal and prevention. Na Hazards 25: 259-288.

5. Arkin Y, Gilat A (2000) Dead Sea sinkholes-An ever-developing hazard. Environ Geol 39: 711-722.

6. Tihansky AB (1999) Sinkholes, West-Central Florida. In: Land Subsidence in the United States, USFS Circular 1182: 121-140.

7. Frumkin A (2013) Salt karst. In: Treatise on Geomorphology, Academic Press, San Diego, USA 3: 407-424.

8. Bruthans J, Filippi M, Asadi N, Zare M, Šlechta S, et al. (2009) Surficial deposits on salt diapirs (Zagros Mountains and Persian Gulf Platform, Iran): Characterization, evolution, erosion and the influence on landscape morphology. Geomorphology 107: 195-209.

9. Dreybrodt W (2004) Dissolution: evaporite and carbonate rocks. Encyclopedia of caves and karst science. Fitzroy Dearborn, New York, USA, pp: 295-300.

10. De Waele J, Mucedda M, Montanaro L (2009) Morphology and origin of coastal karst landforms in Miocene and Quaternary carbonate rocks along the central western coast of Sardinia (Italy). Geomorphology 106: 26-34.

11. Ford D, Williams P (2007) Karst hydrogeology. In: Karst Hydrogeology and Geomorphology, John Wiley \& Sons Ltd., West Sussex, UK, pp: 145-208.

12. Kaufmann G, Romanov D, Nielbock R (2011) Cave detection using multiple geophysical methods: Unicorn cave, Harz Mountains, Germany. Geophysics 76: 71-77.

13. www.haaretz.com/st/c/prod/global/deadsea/eng/5/
14. Abelson M, Yechieli Y, Crouvi O, Baer G, Wachs D, et al. (2006) Evolution of the Dead Sea sinkholes. Geol Soc Am Special Papers 401: 241-253.

15. Lewis $\mathrm{T}$ (2015) Why dangerous sinkholes keep appearing along the Dead Sea.

16. Yechieli Y, Wachs D, Abelson M, Crouvi O, Shtivelman V, et al. (2002) Formation of sinkholes along the shore of the Dead Sea-Summary of the first stage of investigation. Geol Surv Israel Curr Res 13: 1-6.

17. Frumkin A, Raz E (2001) Collapse and subsidence associated with salt karstification along the Dead Sea. Carbonates and Evaporites 16: 117-130.

18. Lucha P, Cardona F, Gutiérrez F, Guerrero J (2008) Natural and humaninduced dissolution and subsidence processes in the salt outcrop of the Cardona Diapir (NE Spain). Environ Geol 53: 1023-1035.

19. Ezersky MG, Eppelbaum LV, Al-Zoubi A, Keydar S, Abueladas A, et al. (2013) Geophysical prediction and following development sinkholes in two Dead Sea areas, Israel and Jordan. Environ Earth Sci 70: 1463-1478.

20. Ezersky M, Frumkin A (2013) Fault-dissolution front relations and the Dead Sea sinkhole problem. Geomorphology 201: 35-44.

21. Shalev E, Vladimir L, Yechieli Y (2006) Salt dissolution and sinkhole formation along the Dead Sea shore. J Geophys Res Vol: 111.

22. Ezersky M, Legchenko A, Al-Zoubi A, Levi L, Akkawi E, et al. (2011) TEM study of the geoelectrical structure and groundwater salinity of the Nahal Hever sinkhole site, Dead Sea shore, Israel. J Appl Geophys 75: 99-112.

23. Ben-Dor E, Goldshleger N, Eshel M, Mirablis V, Basson U (2008) Combined active and passive remote sensing methods for assessing soil salinity. In: Remote Sensing of Soil Salinization. Impact and Land Management, CRC Press, USA, pp: 235-255.

24. Basson U (1992) Mapping of moisture content and structure of unsaturated sand layers with ground penetrating radar. Thesis submitted for the degree of Master of Sciences in Geophysics, Tel-Aviv University, Israel.

25. Mellett JS (1995) Ground penetrating radar applications in engineering, environmental management, and geology. J Appl Geophys 33: 157-166.

26. Neal A (2004) Ground-penetrating radar and its use in sedimentology: Principles, problems and progress. Earth Science Rev 66: 261-330. 